\title{
Implementing Feedback Granule Size Control in a Continuous Dry Granulation Line Using Controlled Impeller Speed of the Granulation Unit, Compaction Force and Gap Width
}

\author{
Annika Wilms ${ }^{1,2} \cdot$ Andreas Teske $^{3} \cdot$ Robin $^{\text {Meier }}{ }^{3} \cdot$ Raphael Wiedey $^{1} \cdot$ Peter Kleinebudde $^{1}$ (D) \\ Accepted: 29 November 2020 / Published online: 17 December 2020 \\ (C) The Author(s) 2020
}

\begin{abstract}
Purpose In continuous manufacturing of pharmaceuticals, dry granulation is of interest because of its large throughput capacity and energy efficiency. In order to manufacture solid oral dosage forms continuously, valid control strategies for critical quality attributes should be established. To this date, there are no published control strategies for granule size distribution in continuous dry granulation.

Methods In-line laser diffraction was used to determine the size of granules in a continuous roll compaction/dry granulation line (QbCon ${ }^{\circledR}$ dry). Different process parameters were evaluated regarding their influences on granule size. The identified critical process parameters were then incorporated into control strategies. The uncontrolled and the controlled processes were compared based on the resulting granule size. In both processes, a process parameter was changed to induce a shift in median particle size and the controller had to counteract this shift.

Results In principle, all process parameters that affect the median particle size could also be used to control the particle size in a dry granulation process. The sieve impeller speed was found to be well suited to control the median particle size as it reacts fast and can be controlled independently of the throughput or material.

Conclusion The median particle size in continuous roll compaction can be controlled by adjusting process parameters depending on real-time granule size measurements. The method has to be validated and explored further to identify critical requirements to the material and environmental conditions.
\end{abstract}

Keywords Continuous manufacturing · Roll compaction/dry granulation · Process analytical technologies · Laser diffraction · Process control $\cdot$ Feedback control

\section{Introduction}

Continuous manufacturing (CM) in the production of pharmaceutical solid oral dosage forms is characterized by the connection of individual processes into one line, ideally from raw excipients and active pharmaceutical ingredient (API) to final

Peter Kleinebudde

kleinebudde@hhu.de

1 Heinrich Heine University Düsseldorf, Universitätsstraße 1, 40225 Düsseldorf, Germany

2 INVITE GmbH, Drug Delivery Innovation Center, Chempark Building W32, 51368 Leverkusen, Germany

3 L.B. Bohle Maschinen + Verfahren $\mathrm{GmbH}$, Industriestraße 18, 59320 Ennigerloh, Germany dosage form. Potentials of this production concept include higher flexibility of production volume and time as well as increased quality due to tight monitoring and control strategies [1-4]. Regulatory agencies and the International Council of Harmonization (ICH) have shown support of this approach [5-11]. A new guideline, ICH Q13, is currently developed for continuous manufacturing processes [12]. However, monitoring and control strategies have to be developed by the manufacturers prior to taking advantage of this manufacturing technique. High priority is set to process-analytical technologies (PAT) which aim at executing timely (in-line or on-line) measurements and determining critical quality attributes (CQA) [13]. As described by the U.S. FDA, in-line measurements are characterized by the sample not being removed from the process [6]. Using this concept, time and resources can be drastically reduced. As a necessary premise, traditional 
characterization techniques (e.g. particle size or API concentration determination) have to be transferred to robust realtime measurements [14].

While direct compression is the favorable process in continuous manufacturing, it is not always possible due to the raw materials properties (especially poor flow properties or segregation issues of powder material). Therefore, a granulation step might be needed prior to tableting. The manufacturing classification system (MCS) is a joint effort from academic and industrial technology experts to rank the feasibility of pharmaceutical processing routes for solid dosage forms. It ranks roll compaction/dry granulation (RCDG) as the granulation method of choice, if direct compression is not possible [15]. It is favorable due to its natural continuity, large throughput possibilities and energy efficiency [16]. It is however not suitable for all formulations as the capability of improving the flow properties is limited based on the large amount of fines in the final granules and the undesired effect of reduced tabletability that is well described in literature [17-19]. A CQA in granulation is the granule size distribution (GSD) of the granulated material $[20,21]$. While there are multiple measurement principles and apparatuses, most of them are set up in a discontinuous way and do not allow continuous GSDdetermination. However, due to the growing interest there have been reports of continuous size determination in the production of pharmaceuticals [22-27]. Size determination has proven to be challenging in continuous RCDG due to the high throughput, the bimodal size distribution with a large fraction of fines and the inhomogeneous product stream [28-32]. The use of laser diffraction, as a non-invasive, in- and on-line technique to monitor the GSD during continuous RCDG was recently published [33].

However, monitoring is only the first step to a process control strategy. To develop a control strategy, a CQA has to be adequately measured first. Afterwards, it is necessary to determine a specification window for the CQA and to find a process parameter that can be controlled which affects the CQA in a desired way. It is well known that the specific compaction force (SCF) and gap width affect the GSD of dry granulated material [34]. However, especially the SCF is a key critical process parameter (CPP) that affects further properties (e.g. hardness [35], porosity [36, 37] and throughput [38] if only the SCF is changed).

Singh et al. (2012) [39] mentioned that the particle size in continuous RCDG could be controlled by adjusting the milling speed of the granulation unit. This claim was statistically analyzed by Mangal et al. in 2018 [40]. The group confirmed that the impeller speed of a conical sieve in the milling unit of a roll compactor has significant impact on the median particle size and the amount of fines. This was evaluated for three different raw materials and two formulations containing ibuprofen and acetaminophen as active pharmaceutical ingredient (API). Mangal claimed that high impeller speeds should be avoided as it could lead to large amount of fines and slow speeds could bear issues in milling the material in adequate time. However, these claims were not backed with data and should be evaluated further.

For a CPP that influences the granule size, it should be possible to program a controller to react to changes in the desired CQA by adjusting the chosen process parameter. Examples of PAT-controllers in pharmaceutical manufacturing, e.g. in fluidized bed processes, can be found in literature $[41,42]$.

The aim of this study was to advance the previously published monitoring strategy for GSD in continuous dry granulation to a control strategy [33]. The proof of principle was supposed to be given for various parameters to be controlled. Therefore, process parameters in RCDG were evaluated for their suitability as control valves. Controller parameters and data analysis were optimized to evaluate the applicability in industrial manufacturing. Implementing a control strategy for granule size in continuous granulation is the next step in the continuous process of implementing advanced manufacturing techniques in the pharmaceutical industry.

\section{Materials and Methods}

\section{Materials}

Microcrystalline cellulose (MCC, Vivapur® 102, JRS Pharma, Germany) was used as a plastically deforming excipient in experiments studying varying process parameters.

For various experiments, magnesium stearate (Parteck LUB MST, Merck, Germany) was added at $1 \%$ for lubrication. To avoid sticking of the material to the rolls, magnesium stearate was mixed with formulation components in a bin blender (LM 40, L.B. Bohle Maschinen + Verfahren GmbH, Germany) for $3 \mathrm{~min}$ at $20 \mathrm{rpm}$. In some experiments the behavior of over-lubricated mixtures was studied. These were produced by increasing the mixing time to $20 \mathrm{~min}$.

For studies using an API in a formulation, 25\% Diclofenac (Amoli Organics Pvt. Ltd., India), 60\% MCC and 14\% anhydrous $\beta$-lactose (SuperTab® ${ }^{\circledR}$ AN, DFE Pharma, Germany) were blended for $20 \mathrm{~min}$ at $20 \mathrm{rpm}$. Afterwards, $1 \%$ magnesium-stearate was added and blended for another $3 \mathrm{~min}$.

\section{Continuous Roll Compaction/Dry Granulation}

$\mathrm{A} \mathrm{QbCon} \odot$ dry $\mathrm{CM}$-line was used for all experiments. It was equipped with a small-scale roll compactor (BRC 25, L.B. Bohle Maschinen + Verfahren GmbH, Germany). A $360^{\circ}$ rotating conical sieve was implemented as granulation unit and comprised a $1.0 \mathrm{~mm}$ rasp sieve (BTS 100, L.B. Bohle Maschinen + Verfahren GmbH, Germany). Knurled surface rolls and a hybrid sealing system were used for all 
experiments. $2 \mathrm{rpm}$ roll speed was set for all experiments. Material was refilled manually. A suction shoe was mounted below the roll compactor outlet and attached to a plastic hose (see Fig. 1, points 7 and 8). The hose was linked to a vacuum receiver (Volkmann GmbH, Soest, Germany) and the applied vacuum continuously transported the granules through the laser diffraction system into a collection vessel. If the fill volume exceeded a capacity maximum, the vacuum receiver stopped for ten seconds, the vessel was emptied and afterwards conveyance continued.

Based on their impact on the resulting GSD, several process parameters were evaluated in this study. The impeller speed of the granulation unit can be varied between 0 and $900 \mathrm{rpm}$. To determine its effect on particle size, the full spectrum was evaluated in increments of $100 \mathrm{rpm}$. The SCF to be evaluated were chosen based on literature. Wiedey et al. applied SCF between 2 and $10 \mathrm{kN} / \mathrm{cm}$ to $\mathrm{MCC}$ in a study, which was designed to cover all feasible SCF generating a stable process [34]. As tensile strength values of the resulting tablets decrease at increasing SCF, which could result in tablets of insufficient strength, values of SCF between 2 and $6 \mathrm{kN} / \mathrm{cm}$ were chosen in this study. Inducing a process instability (e.g. a change in SCF) will affect the stability of the gap width during compaction. These changes will trigger a gap width fluctuation of up to $1 \mathrm{~mm}$, while in a constant process, the fluctuation can be below $0.1 \mathrm{~mm}$ [33]. Therefore, gap with between 1.5 and $2.5 \mathrm{~mm}$ were explored in the scope of this study.

\section{Granule Size Determination Using Laser Diffraction}

An in-line laser diffraction system (Insitec@ T, Malvern Panalytical, UK) was instrumented (see Fig. 1, point 9).

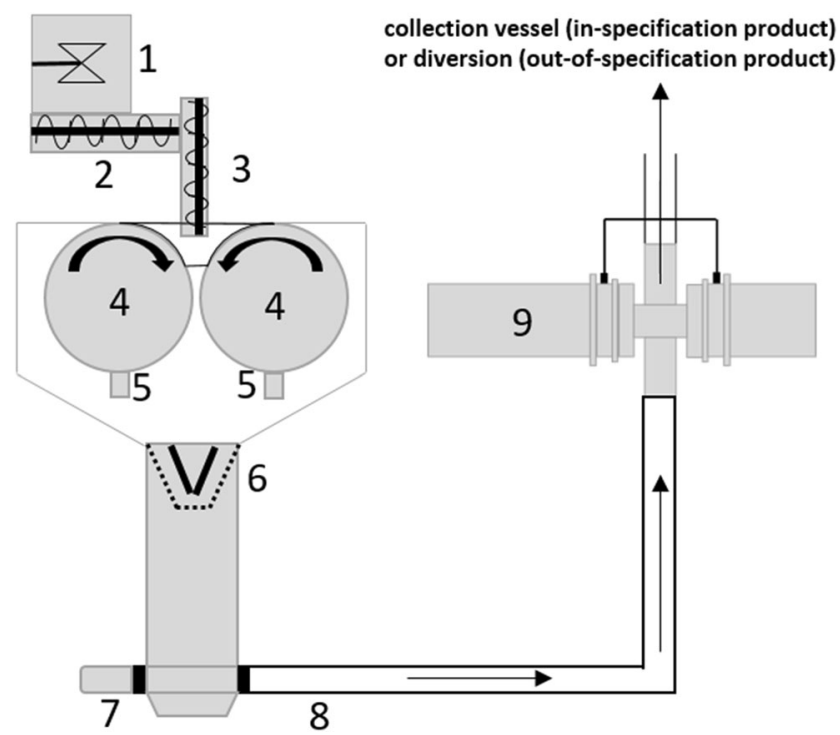

Fig. 1 Experimental set-up 1) powder inlet, 2) feeding auger, 3) tamping auger, 4) rolls, 5) scraper, 6) conical sieve, 7) suction shoe, 8) plastic hose, 9) laser diffraction system
The hose attached to the outlet of the roll compactor lead the material through the installation before reaching the collection vessel. As no material is diverted for analysis and the complete product stream is led through the laser diffraction system, the set-up is classified as in-line. As the laser diffraction system is implemented in the pneumatic transport system and there is no direct contact to the granules, it is a non-invasive technique. The system can analyze particles up to a diameter of $1600 \mu \mathrm{m}$. It contains a lens of $500 \mathrm{~mm}$ focal length, a laser (red, $670 \mathrm{~nm}$ ) with a $10.0 \mathrm{~mm}$ beam waist, a circular detector comprising 33 detector plates and a scan rate of $2000 \mathrm{~Hz}$. The system logged the GSD data with a frequency of $0.2 \mathrm{~Hz}$ equaling to a displayed value every $5 \mathrm{~s}$, which comprised 10,000 individual scans. Raw data was tracked and exported using RTSizer@ software (Malvern Panalytical, UK). To avoid lens fouling a constant stream of pressured air was inserted on both lenses $\left(10 \mathrm{Nm}^{3} / \mathrm{h}\right)$ and drained off together with the material stream.

\section{Process Control}

The granule size data was logged with MalvernLink@ software (MalvernPanalytical, UK) and synchronized via OPC UA to a SCADA server (L.B. Bohle Maschinen + Verfahren $\mathrm{GmbH}$, Germany). Individual values of transmission as well as characteristic quantiles (D25, D50, D75, D90) were transmitted. Furthermore, moving average ( $90 \mathrm{~s}$ ) values were transmitted for all of the named parameters. The moving average over $90 \mathrm{~s}$ was chosen as GSD parameter to be controlled in order to smoothen the natural fluctuations.

A proportional-integral (PI) controller was programmed to compare the current value with the set-point value, calculate the error and generate a response. The formula of a PIcontroller is shown in eq. 1 . The control signal addressed to the actuator (c) is calculated [43].

$c=\mathrm{c}_{0}+K_{c}\left(e+\frac{1}{T_{i}} \int_{0}^{1} e(\tau) d \tau\right)$

$c_{0}$ is a constant controller bias (or null signal) which assures a smooth transition from turning on the controller. Typically, it equals $c$ at the time point of turning on the controller. $e$ represents the current error (current value - set point) at time point $\tau . K_{c}$ (gain-factor) and $T_{i}$ (integral time) could be varied for optimization of the controller. They characterize the proportional and integral part of the controller respectively [43]. The desired particle size value was entered in the software. Three controllers were programmed, each controlling a different process parameter (SCF, gap width and impeller speed of the milling unit). $K_{c}$ and $T_{i}$ values are listed with every experiment in the Results section. 


\section{Data Treatment}

For evaluation of possible control variables, GSD data was logged every $5 \mathrm{~s}$. Depending on run-time during the experiment, 48 to 72 values were logged corresponding to experimental run times between 4 to $6 \mathrm{~min}$. If a run was executed 3 times and lasted $6 \mathrm{~min}$ each, the amount of data points is specified as $n=3 \times 72$.

For analysis of a continuous process, the RCDG process parameters and the GSD data were logged together every second. For time against parameter graphs the $90 \mathrm{~s}$ moving average for GSD data is plotted. The process parameters are plotted as individual, non-smoothed values $(n=1)$.

To evaluate the distribution of GSD values in one process, a density against particle size plot was chosen. All GSD values recorded over the time span of the experiment were normalized to the desired set-point that was chosen for the experiment. Afterwards, the density of each relative particle size (D50/D50 mean) was estimated using kernel density estimation and plotted. The data analysis was performed using functions of Pythons Pandas library (python 3.8, python.org; Pandas 1. 1.0 , pandas.pydata.org).

\section{Results and Discussion}

\section{Determination of Suitable Control Variables for Different Material Types}

The effect of varying CPPs on GSD was evaluated using MCC and a formulation containing Diclofenac. As mentioned in the introduction, Mangal et al. reported that increasing the impeller speed decreases the particle size of granules [40]. In their work, the factor space was limited to 300,600 and $900 \mathrm{rpm}$ impeller speed. To develop a control strategy based on this effect, it was analyzed in more detail for this work. Therefore, the impeller speed was increased from $100 \mathrm{rpm}$ to $900 \mathrm{rpm}$ in $100 \mathrm{rpm}$ intervals and the resulting granule size was measured. Before each measurement, the sieve was vacuumed to be empty and the measurement was started when the system was in equilibrium. Every individual measurement lasted 4-6 min (48-72 individual values). Results are shown in Fig. 2.

In contrast to Mangal [40], the effect of the impeller speed on particle size was not found to be solely a decrease in particle size at increasing impeller speeds. A maximum in particle size was observed at 300-500 rpm. Decreasing and increasing the impeller speed from there decreased the granule size parameters. With the experimental settings chosen by Mangal, this effect could not be visible in the statistical design of experiment chosen.

Figure $2 \mathrm{~b}$ ) clearly shows a large variation at different impeller speeds for MCC compacted at $4 \mathrm{kN} / \mathrm{cm}$. In Fig. 2 d), the
6 repetitions are shown individually. For every individual measurement, the curve has an inverted u-shape with a maximum for D50. However, the absolute values differ.

A possible explanation, as MCC is a hygroscopic material, could be the varying air humidity in the laboratory facility. The effect of moisture content on MCC characteristic properties was extensively studied by Sun $[44,45]$. In one of the studies, MCC was equilibrated between 0 and $84.3 \%$ RH. Afterwards, compressibility plots of the materials were compared. If the monolayer water coverage was exceeded $(26 \%$ $\mathrm{RH}$ at $25^{\circ} \mathrm{C}$ ), the compressibility plots depended on water content of MCC. A higher water content of MCC led to a reduced porosity and a faster approach to zero porosity at increasing pressure [44].

As the compressibility plot describes the change in porosity upon pressure, this variety can also be applicable to the roll compaction process. The temperature was controlled at $23^{\circ} \mathrm{C}$. However, air humidity was not controlled. In Fig. 2 d), the empty triangles were recorded at $37 \% \mathrm{RH}$ while the results plotted as empty circles were recorded at $50 \%$ RH. It is possible that the monolayer water coverage was exceeded for parts or all of the material, however, measurements were not performed. Therefore, in accordance with the research by Sun, during the experiment at 50\% RH, MCC was compressed to a ribbon showing less porosity compared to the experiment conducted at $37 \%$ RH. The observed differences in resulting granule sizes are then plausible [34]. For the results plotted as filled circles, the relative humidity was not tracked. It is recommended to perform experiments in a temperature and air humidity-controlled environment and track these values if they cannot be controlled. For the research presented in this work, the results meant that absolute particle sizes registered have to be analyzed in accordance with the day experiments were conducted. Figure $2 \mathrm{c}$ ) shows the results for a formulation containing Diclofenac as API. The curves have a similar shape as those of pure MCC. The values in Fig. 2 c) were, opposed to Fig. 2 a) and b), recorded on a single day.

ANOVA was performed and results are shown in Table 1. For MCC compacted at 2 and $4 \mathrm{kN} / \mathrm{cm}$ trends were observed, but it could not be stated with statistical significance that the impeller speed has any effect on granule size. For the Diclofenac formulation, all three granule size values are significantly impacted by impeller speed. For individual measurement runs (Fig. 4 d)) the statistical analysis could not be performed as individual values of $n=1$ cannot be statistically analyzed comparably. The insufficient repeatability for MCC compacted at $4 \mathrm{kN} / \mathrm{cm}$ has to be evaluated further in future research.

For controlling the granule size by adjusting the impeller speed of the milling unit, a direction of action has to be defined. Therefore, the impeller speed controller was limited to either $100-400 \mathrm{rpm}$ or $400-900 \mathrm{rpm}$ and the direction (increasing or decreasing the impeller speed at deviation 
Fig. 2 GSD parameters against impeller speed. a), b) and c): black = D90; gray $=\mathrm{D} 75$; light gray $=\mathrm{D} 50$. a) $\mathrm{MCC}, 2 \mathrm{kN} / \mathrm{cm}$; $n=3 \times 72 ;$ mean \pm sd. b) MCC, 4 $\mathrm{kN} / \mathrm{cm} ; n=6 \times 48-72 ;$ mean $\pm \mathrm{sd}$. c) Diclofenac formulation, $7 \mathrm{kN} /$ $\mathrm{cm} ; \mathrm{n}=3 \times 48$; mean \pm sd. d) individual D50-values for MCC at 4 $\mathrm{kN} / \mathrm{cm}$. Each symbol represents an individual experiment. Each data point $n=48-72$; mean
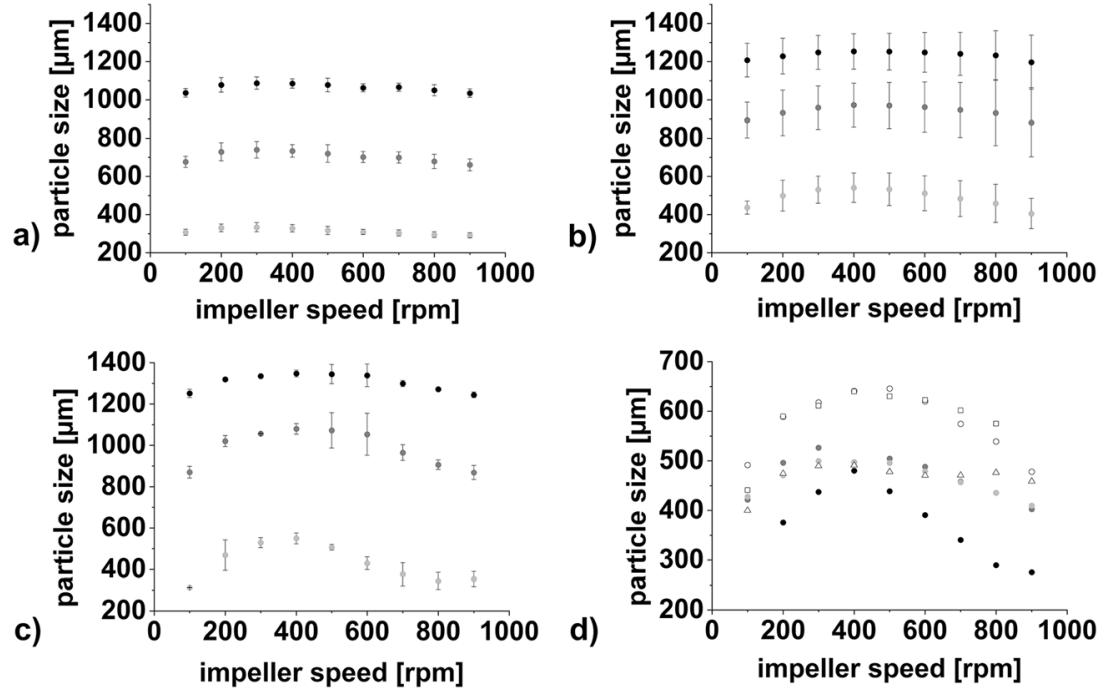

from set-point) was defined by using a positive or a negative $K_{c}$-value.

It can be seen in Fig. 2 that the impact of impeller speed on particle size is limited, as the slopes of the increasing and decreasing part of the curve is low. As known from literature, the CPPs SCF and gap width have an impact on the resulting granule sizes. In scope of this work, the impact of both parameters on the resulting median particle size (D50) was measured using in-line laser diffraction for MCC as excipient (Fig. 3).

In conclusion, impeller speed, gap width and SCF are CPP that impact the resulting granule size. Based on these results, there needs to be a proof that this behavior can be used to control a process in accordance with granule size. There was no impact of impeller speed on the granule size at low SCF (2 $\mathrm{kN} / \mathrm{cm}$, see Table 1). At $4 \mathrm{kN} / \mathrm{cm}$, the impact was visible for individual measurement runs, however, insufficient repeatability impacts a general conclusion. The decision, which

Table 1 Results of ANOVA for data shown in Fig. 2 a) - c). Diclo= Diclofenac formulation; $\mathrm{DF}=$ degrees of freedom; $\mathrm{SSQ}=$ sum of squares; Mean $\mathrm{Sq}=$ mean sum of squares; $\mathrm{F}$ emp $=$ calculated $\mathrm{F}$-value; $p$ value $=$ calculated $\mathrm{p}$ value

\begin{tabular}{|c|c|c|c|c|c|c|c|}
\hline SCF & material & $\mathrm{Dx}[\mu \mathrm{m}]$ & DF & SSQ & Mean Sq & F emp & $p$ value \\
\hline \multirow[t]{3}{*}{2} & \multirow[t]{6}{*}{$\mathrm{MCC}$} & 50 & 8 & 5761.5 & 720.2 & 2.236 & 0.0745 \\
\hline & & 75 & 8 & $19,051.3$ & 2381.4 & 1.755 & 0.1531 \\
\hline & & 90 & 8 & 9538.6 & 1192.3 & 1.515 & 0.2204 \\
\hline \multirow[t]{3}{*}{4} & & 50 & 8 & $95,940.5$ & $11,992.6$ & 1.775 & 0.1088 \\
\hline & & 75 & 8 & $45,001.6$ & 5625.2 & 0.315 & 0.9563 \\
\hline & & 90 & 8 & $17,437.3$ & 2179.7 & 0.193 & 0.9904 \\
\hline \multirow[t]{3}{*}{7} & \multirow[t]{3}{*}{ Diclo } & 50 & 8 & $158,137.5$ & $19,767.2$ & 13.626 & $<0.0001$ \\
\hline & & 75 & 8 & $163,348.6$ & $20,418.6$ & 6.936 & 0.0007 \\
\hline & & 90 & 8 & $35,913.9$ & 4489.2 & 5.480 & 0.0023 \\
\hline
\end{tabular}

process parameter is suited to control the granule size must be evaluated carefully prior to implementing the control loop.

\section{Controlling a Process with an Unstable Gap Width - Impeller Speed Controller}

A change in gap width leads to a change in resulting particle size (Fig. 3 b). An unstable gap can be the result of poorly flowing materials for which even feeding is difficult. It was evaluated whether the control tool can counteract the changes in GSD caused by an unstable gap. Therefore, in a reference experiment, $\mathrm{MCC}$ was compacted at $2 \mathrm{kN} / \mathrm{cm} \mathrm{SCF}, 800 \mathrm{rpm}$ impeller speed and $2 \mathrm{~mm}$ gap width for $15 \mathrm{~min}$. After $15 \mathrm{~min}$ the gap width was increased to $2.5 \mathrm{~mm}$ at otherwise constant process parameters. Results can be seen in Fig. 4 a). As expected, the D50 values that are registered dropped after an increase in gap width. During the first $15 \mathrm{~min}$, at $2.0 \mathrm{~mm}$ gap width, the average D50 value recorded was $440 \mu \mathrm{m}$. Therefore, $440 \mu \mathrm{m}$ was chosen as set-point for the experiments under controlled conditions (horizontal dashed lines in Fig. 4). Figures 4 b) and c) show results of the same experimental set-up but with a controlled impeller speed. The two experiments differ in the proportional controller gain $\left(K_{c}\right)$. The controller set at $K_{c}=-1.0$ is more aggressive than the one set at $K_{c}=-0.5$.

In both cases, the drop in particle size can be counteracted by the controller adjusting the impeller speed (Fig. 4 d)). To evaluate the effect in more detail, the density against relative particle size plot is shown in Fig. 5. In the uncontrolled process, the density curve shows a bimodal shape indicating that two particle sizes are dominant. One is located at $1(=440 \mu \mathrm{m})$ and the second one is located at about $0.86(\approx 378 \mu \mathrm{m})$. Based on the experimental procedure and results (Fig. 4 a)) it is obvious that the first peak at 1 indicates the average particle size at $2.0 \mathrm{~mm}$ gap width while the second peak can be 
Fig. 3 Median particle size (D50) against a) SCF (constant roll speed $=2 \mathrm{rpm}$, gap width $=$ $2.0 \mathrm{~mm}$ and impeller speed $=$ $800 \mathrm{rpm})$ and b) gap width (constant roll speed $=2 \mathrm{rpm}, \mathrm{SCF}=$ $4.0 \mathrm{kN} / \mathrm{cm}$ and impeller speed $=$ $800 \mathrm{rpm})$ for MCC. Each point $n=1 \times 72 ;$ mean \pm sd

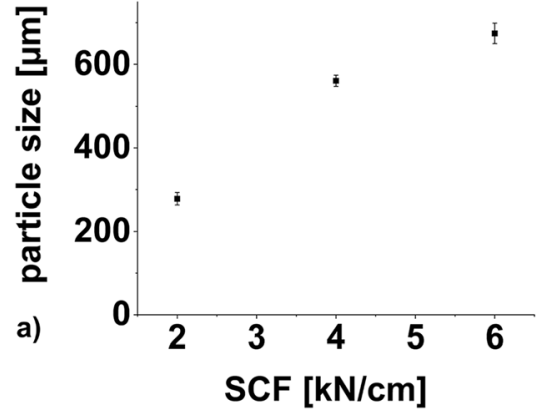

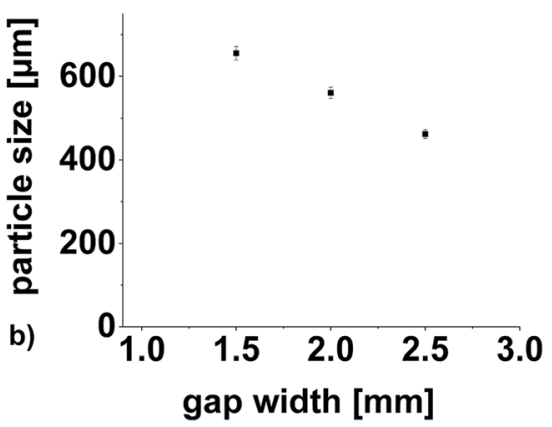

attributed to compacting the material at $2.5 \mathrm{~mm}$ gap width. When the process is controlled, the peak at 0.86 relative particle size is no longer visible. The curves show a slightly different shape, as the more aggressive controller tends to over- and under-shoot leading to a bimodal shape slightly above and below 1. The less aggressive controller has a mono-modal curve shape centered at 1 , as desired. However, it has a broader distribution ranging from 0.85 to 1.13 . The initial drop in particle size that triggered the controller response can be seen approximately at 0.95 relative particle size.

In Fig. 4 b) and c), the sieve speed drops to the minimum of $400 \mathrm{rpm}$ on two occasions each. This is a result of the experimental set-up (see section II.2. Continuous roll compaction/ dry granulation) and the collection vessel in which all material is collected. If the fill level of the vessel reaches a threshold, the vessel is emptied. For this process, the pneumatic transport of material is interrupted for approximately $10 \mathrm{~s}$. Therefore, for two individual measurements, no granule sizes can be measured, as no granules pass through the laser beam. Unfortunately, on these occasions, a D50 value of $0 \mu \mathrm{m}$ is transmitted to the SCADA server. The sudden decrease is D50 value leads to an increased error e and triggers a large control signal $\mathrm{c}$ to the actuator. In this case, a sudden drop in impeller speed occurs (see eq. 1). As pneumatic conveyance restarts after emptying of the vessel, the impeller speed recovers. However, this sudden change in impeller speed can trigger a change in particle size. Therefore, the system is not directly in equilibrium after conveyance restarts. This issue was also addressed in previous research [33]. Programming the software to transmit a blank value instead of $0 \mu \mathrm{m}$ when no particles were measured, a larger collection vessel or implementing a rotary valve instead of the vessel are reasonable adjustments that will solve the current issue and should be implemented in further experiments.

\section{Controlling a Process with an Unstable Gap Width - SCF Controller}

It was assumed that an increase in gap width and the following drop in granule size can also be counteracted by controlling
Fig. 4 Plot of D50 and impeller speed against time. a) uncontrolled process $b$ ) controlled at $440 \mu \mathrm{m}, \mathrm{Kc}=-0.5, \mathrm{Ti}=10.0 \mathrm{~s}$ c) controlled at $440 \mu \mathrm{m}, \mathrm{Kc}=$ $-1.0, \mathrm{Ti}=10.0 \mathrm{~s}$ d) D50 values of experiments a) - c) combined. a) $-\mathrm{c})$ black $=$ D50, gray $=$ impeller speed, horizontally dashed = $440 \mu \mathrm{m}$ set-point, vertically dashed $=$ gap width change $\mathrm{d}$ ) black $=$ uncontrolled, dark gray $=$ controlled, $\mathrm{Kc}=-0.5, \mathrm{Ti}=10.0 \mathrm{~s}$, light gray $=$ controlled, $\mathrm{Kc}=-0.5$, $\mathrm{Ti}=10.0 \mathrm{~s}$. Each data point $n=1$; in-line data
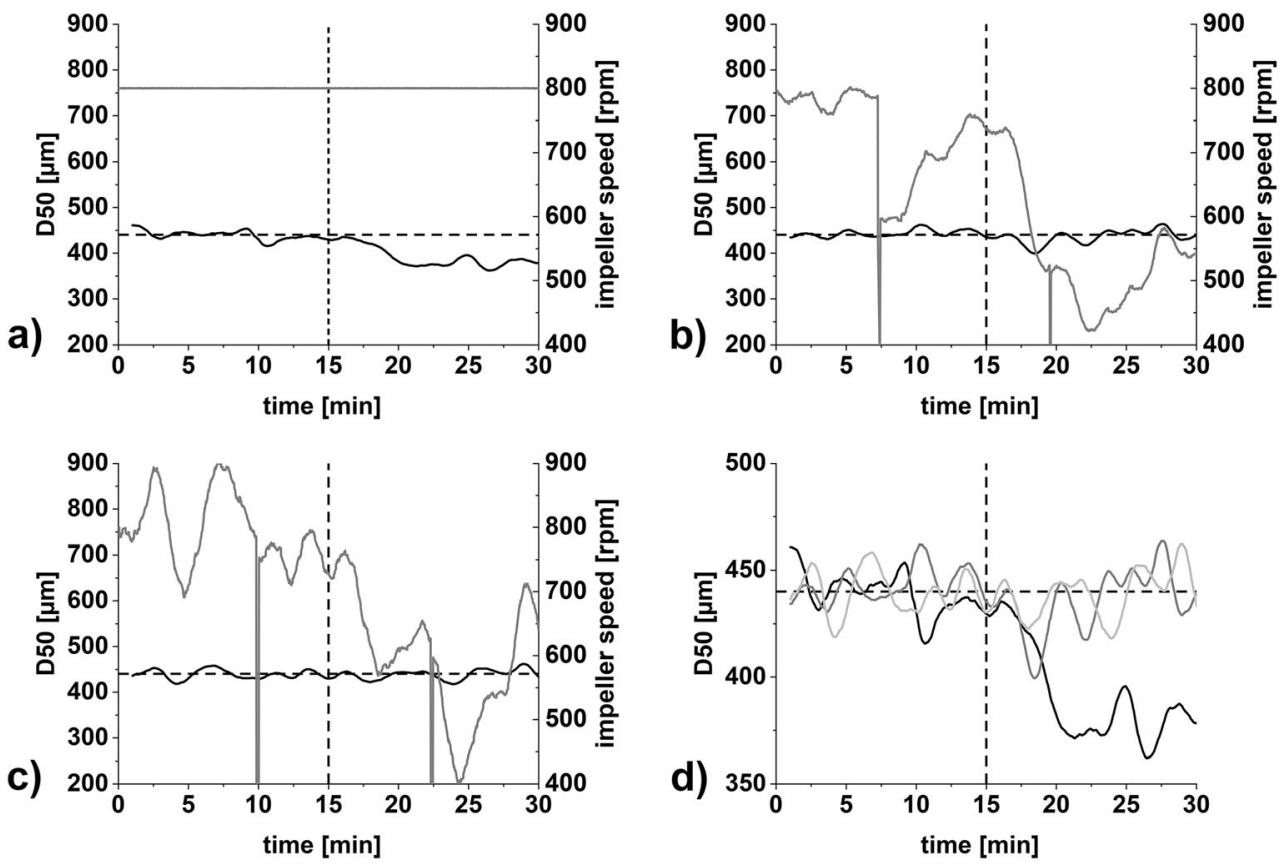


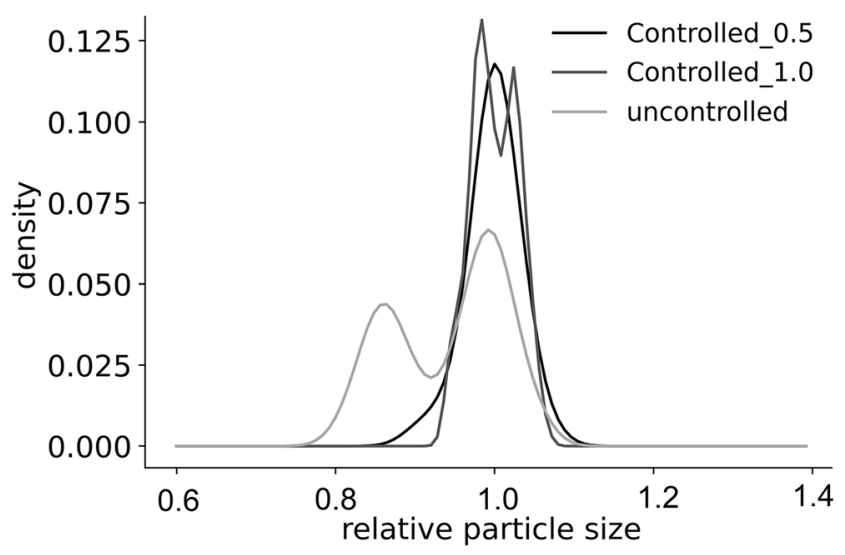

Fig. 5 Density against relative particle size for the experiments shown in Fig. 4 a) -c). Each plot $n=1$; in-line data

the SCF. This was proven by repeating the experiments as shown in section II.2 (Controlling a process with an unstable gap width - impeller speed controller) and utilizing an SCF controller instead of an impeller speed controller. The impeller speed was constant at $800 \mathrm{rpm}$. Results are shown in Fig. 6.

As experiments were conducted on the same day, the same data for the uncontrolled process could be used (Fig. 6 a) and Fig. 4 a)). As expected, after increasing the gap width, the SCF of the systems needs to be increased in order to counteract the drop in granule size. The effect of the controller is clearly visible (Fig. 6 b) - d)). As explained in the introduction, changing the SCF during the process is not favorable. In this experiment, the SCF was varied between approximately 4 and 5.8 $\mathrm{kN} / \mathrm{cm}$. This will impact other CQA of the granules, which is not intended.

\section{Controlling a Process with an Unstable SCF - Gap Width Controller}

To evaluate the gap width controller, the experiment had to be adjusted. In a similar manner as discussed before, the SCF was changed after $15 \mathrm{~min}$ to stimulate a drop in particle size. As the SCF is a tightly controlled CPP, a drop in SCF is unusual during granulation. However, it was used in this case to generate a drop in granule size and to test the principle of using a gap width controller to control the GSD. To evaluate the results in comparison with another control valve, the drop in SCF was also counteracted by using a impeller speed controller as presented in section III.2 (controlling a process with an unstable gap width - impeller speed controller). Results are shown in Figs. 7 and 8.

Changing the SCF from 4 to $3.5 \mathrm{kN} / \mathrm{cm}$ led to a drop in the D50 parameter. However, the drop was not as pronounced as in the previous experiments (median particle size decreased from approximately $430 \mu \mathrm{m}$ to $400 \mu \mathrm{m}$ ). The density distribution of the uncontrolled process (gray in Fig. 8 a) shows a peak at 1.0 relative particle size and then a crooked curve along lower relative particle sizes but no sharp second peak. The controlled process was able to produce granules with a mono-modal D50-density curve. Controlling the gap width (Fig. 7 c) and d)) led to satisfying results using a controller with a $K_{c}$ value of -0.0003 and $T_{i}$ value of $10.0 \mathrm{~s}$. The phase shift in reaction is visible in the D50/gap width against time plot (Fig. 7 c) and d)). This shift is visible due to the comparably longer time the change in gap width needs to have an effect on the D50 value. At more aggressive controller settings ( $K_{c}=-0.0006$ and $T_{i}=10.0 \mathrm{~s}$ ), this led to large over
Fig. 6 Plot of D50 and SCF against time. a) uncontrolled process b) controlled at $440 \mu \mathrm{m}$, $\mathrm{Kc}=0.001, \mathrm{Ti}=10.0 \mathrm{~s} \mathrm{c}$ ) D50 values of experiments a) and b) combined. d) density against relative particle size plot for uncontrolled (gray) and SCF controlled (black) experiments a) and b) black $=\mathrm{D} 50$, gray $=\mathrm{SCF}$, horizontally dashed $=440 \mu \mathrm{m}$ set-point, vertically dashed = gap width change. Each data point $\mathrm{n}=1$; in-line data
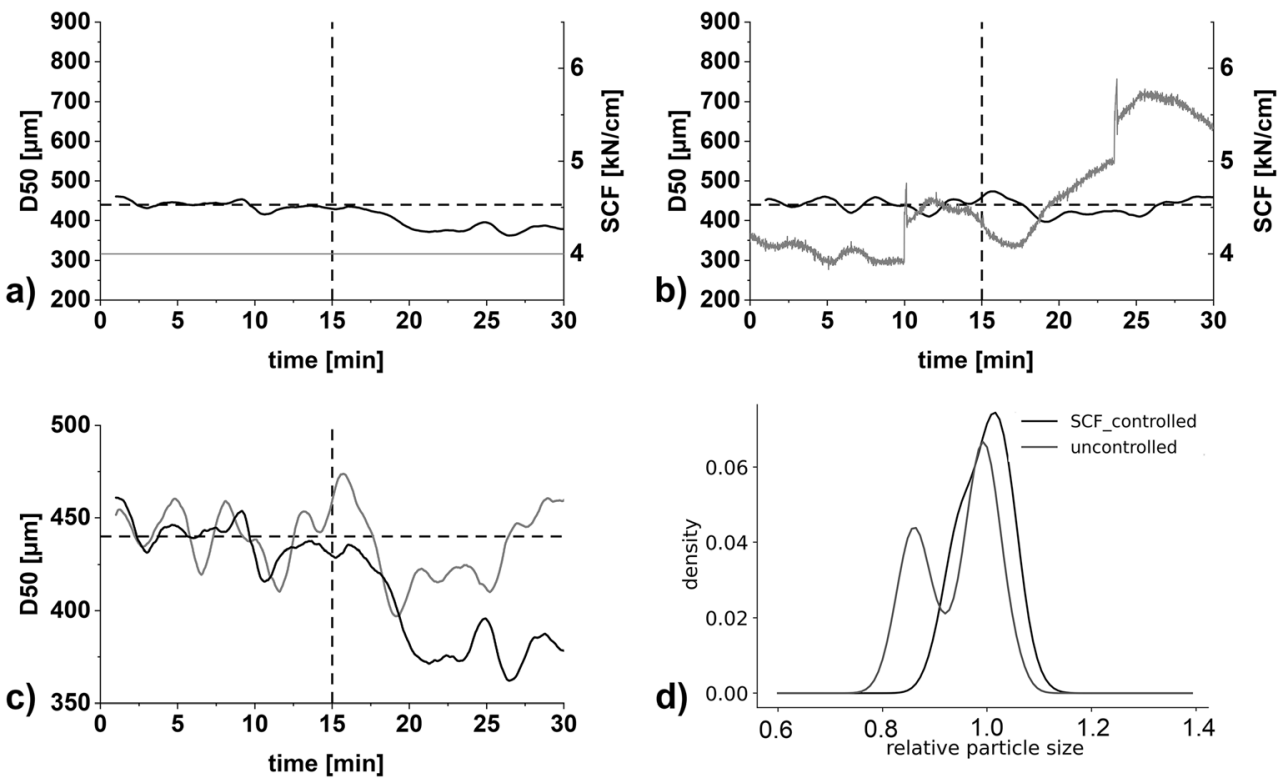
Fig. 7 Plot of D50 and impeller speed or gap width against time. a) uncontrolled process b) impeller speed controlled at $440 \mu \mathrm{m}, \mathrm{Kc}=-0.5, \mathrm{Ti}=10.0 \mathrm{~s} \mathrm{c}$ ) gap width controlled at $440 \mu \mathrm{m}$, $\mathrm{Kc}=-0.0003, \mathrm{Ti}=10.0 \mathrm{~s} \mathrm{~d}$ ) gap width controlled at $440 \mu \mathrm{m}, \mathrm{Kc}=$ $-0.0006, \mathrm{Ti}=10.0 \mathrm{~s}$. black line $=$ D50, a) and b) gray = impeller speed c) and d) gray = gap width, a) - d) black = D50, horizontal dashed line $=$ set-point $(440 \mu \mathrm{m})$, vertical dashed line $=$ change in $\mathrm{SCF}$ (4 to $3.5 \mathrm{kN} / \mathrm{cm}$ ). Each data point $n=1$; in-line data
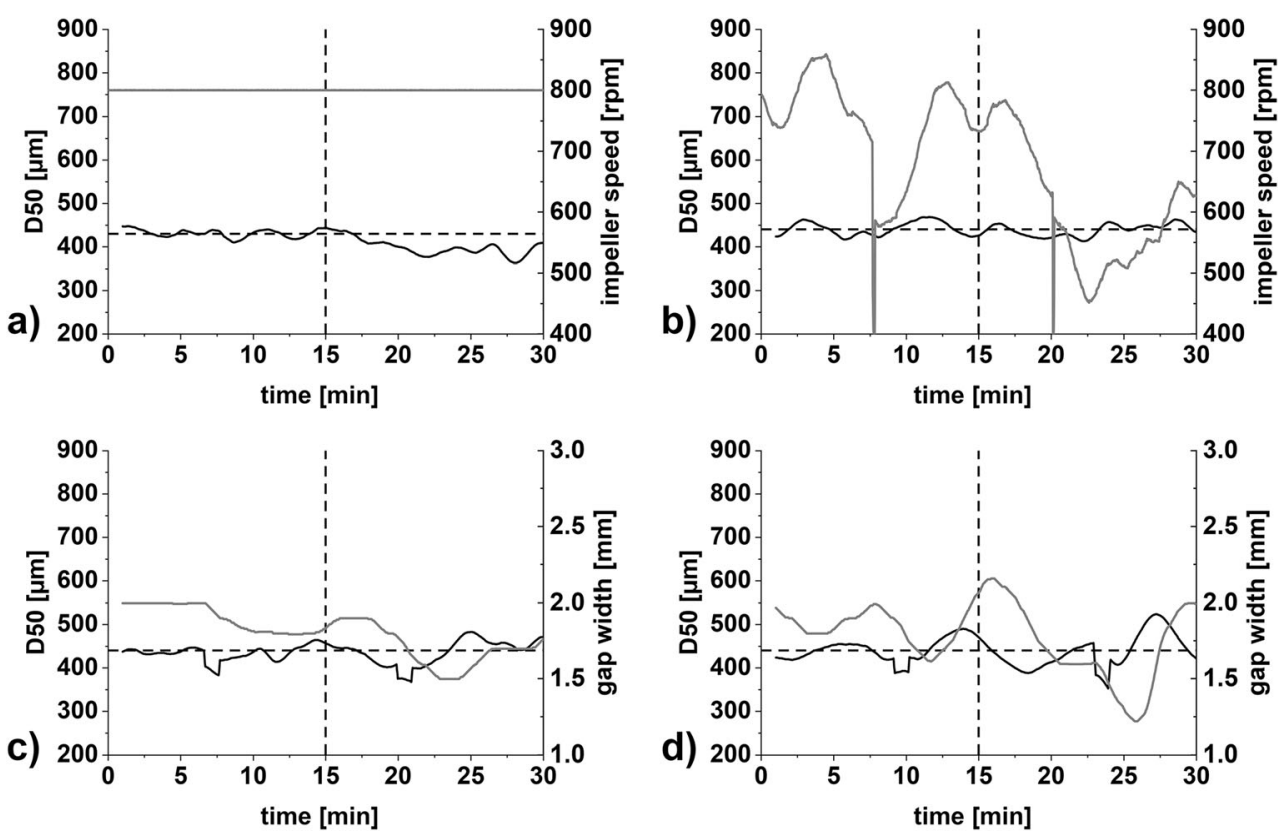

and undershoots of gap width and particle size (Fig. 7 d) and a density curve that is similarly crooked than the uncontrolled one (Fig. 8 b), medium gray curve).

In principle, the gap width can be used to control the D50 parameter in continuous RCDG. However, due to a long response time the controller settings must be carefully evaluated and the risk of over and undershooting is potentially larger than for the impeller speed and SCF controller. This is underlined by the fact that the impeller speed controller generates D50-density curves with a monomodal shape that is distinctively narrower than both gap width controllers. Furthermore, in controlling the SCF of the roller compactor, the gap width is used as control valve (PID controller, $K_{c}=$ $\left.0.0072, T_{i}=2.0 \mathrm{~s}, T_{d}=0.007\right)$. Using the gap width as a control valve for two parameters could lead to conflicts of interest (setting the desired SCF and desired granule size at the same time). Based on this and the results presented, it appears unfavorable to utilize the gap width as control valve albeit it was proven that in principle it is possible.

\section{Controlling a Process with a Properly Lubricated and an over-Lubricated Excipient Blend}

It was previously reported that granulating an over-lubricated formulation significantly decreases the particle size compared to the same formulation with proper lubrication [33]. Within the scope of this work, it was evaluated whether the controllers can counteract this drop in particle size. Therefore, MCC was blended with $1 \%$ Magnesium-stearate, $3 \mathrm{~min}$ at $20 \mathrm{rpm}$ to form a properly lubricated mixture and $20 \mathrm{~min}$ at $20 \mathrm{rpm}$ to form an over-lubricated mixture. The properly lubricated material was granulated first. Then, the over-lubricated mixture was poured into the powder inlet unit. It was waited until the hopper was almost completely empty and the feeding screw of the roll compactor was visible before the over-lubricated mixture was added. That way the extent of back-mixing between two different materials was minimized.

Results are shown in Fig. 9. It is visible that shortly after the over-lubricated mixture was poured into the roll compactor
Fig. 8 Density against relative particle size for the experiments shown in Fig. 9 a) - d). a) uncontrolled and sieve-speed controlled density distribution $b$ ) uncontrolled and gap width controlled density distribution. Each plot $\mathrm{n}=1$; in-line data
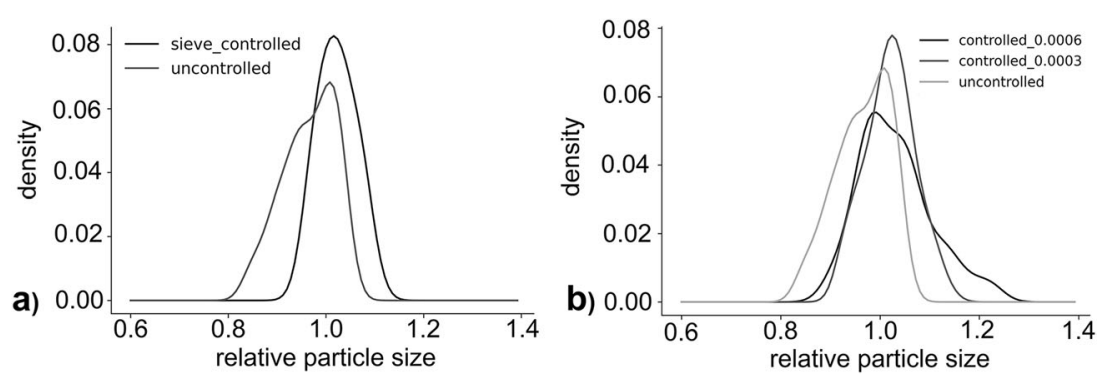


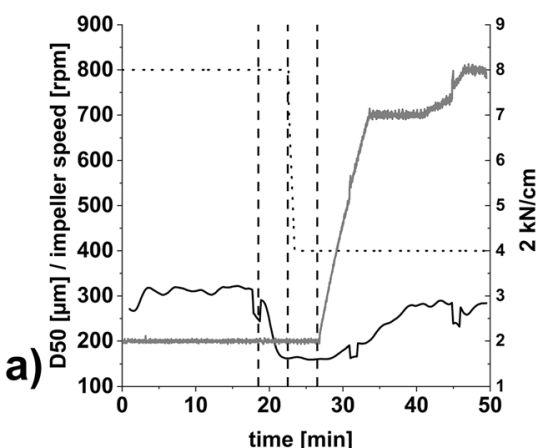

Fig. 9 Plot of D50 (black), impeller speed (black dotted) and SCF (gray) against time. a) $\mathrm{SCF}=2 \mathrm{kN} / \mathrm{cm}$ b) $\mathrm{SCF}=4 \mathrm{kN} / \mathrm{cm}$. First vertical dashed line $=$ addition of the over lubricated mixture, second vertical line $=$ the

the D50 value decreased. If the impeller speed controller was turned on, it reacted to the decreased particle size by lowering the impeller speed until the minimum of $400 \mathrm{rpm}$ was reached. For two SCFs, no effect of impeller speed on the particle size could be registered. Therefore, in both cases, the impeller speed controller was turned off and the SCF controller was turned on. It reacted to the difference between set-point and current value by increasing the SCF. In both cases, the particle size then increased (Table 2).

In both cases, both controllers were unable to shift the granule size back to its original value (Fig. 9 and Table 2). The impeller speed controller had no effect on the granule size of the over-lubricated formulation. The effect of magnesium stearate in over-lubrication is well described in literature, although to this day not fully understood [46-48]. During overlubrication, its main effect is the formation of friable ribbons which show poor mechanical strength and almost disintegrate to powder during milling. It is reasonable to assume that the impeller speed has no effect on the particle size and that the over-lubrication in itself determines the resulting particle size. At increased SCF, the ribbon itself is compacted differently and thereby a certain effect on the resulting granule size is understandable. The large increase of SCF needed to increase the D50-value relevantly underlines this.

Overall, granules that were produced from an over lubricated powder mixture will not be suitable for further processing. The principle of using an SCF controller to counteract the drop in particle size further proofs the controller principle. It also showed that not every excipient and formulation can be controlled by adjusting the impeller speeds. Therefore,

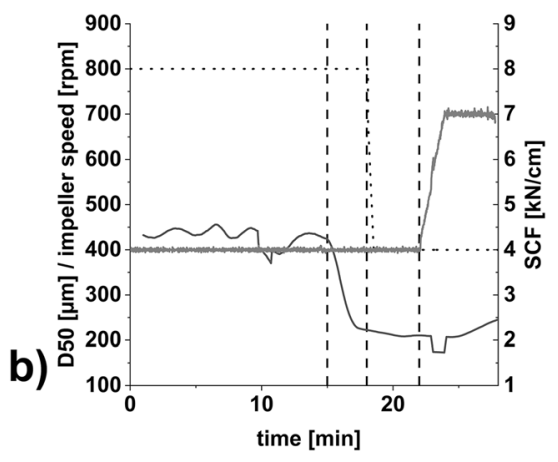

controller of the impeller speed was turned on, third vertical dashed line $=$ the impeller speed controller was turned off and the SCF controller was turned on. Each data point $n=1$; in-line data

recording the particle size at different impeller speeds (as shown in Fig. 2) is an important preliminary experiment to determine a formulations suitability to be impeller-controlled.

\section{Conclusions}

CPP that have an effect on the GSD can be used to control the resulting granule size using feedback control loops. The impeller speed is well suited to be used in control loops as it can be directly set itself, independent from further process parameters and has limited effect on further CQA apart from the granule size. SCF and gap width are parameters that, in principle, can be used to control a granulation process. However, their impact on further CQA and the fact that they are controlled themselves impede this usage. To determine, whether a material can be controlled, it has to be checked, how sensitive the granule size reacts to changes in the chosen control valve process parameter. Limits of this control strategy include the large variability that was seen experimentally and the limited impact of the impeller speed on the granule size. The impact of air humidity on various excipients in the laser diffraction system should be evaluated. Additional experiments should be conducted to evaluate, if there are additional factors that could lead to insufficient reproducibility. Furthermore, advanced strategies to tune the controller should be implemented to optimize the reaction and minimize material out of the desired specification.

Table 2 D50-values during granulation of correct and over-lubricated MCC. $\mathrm{n}=1$; mean

\begin{tabular}{llll}
\hline SCF & Average D50 with correct lubrication & Average D50 with over-lubrification & Max D50 at increased SCF \\
\hline $2 \mathrm{kN} / \mathrm{cm}$ & $313 \mu \mathrm{m}$ & $162 \mu \mathrm{m}$ & $286 \mu \mathrm{m} / 8 \mathrm{kN} / \mathrm{cm}$ \\
$4 \mathrm{kN} / \mathrm{cm}$ & $429 \mu \mathrm{m}$ & $208 \mu \mathrm{m}$ & $246 \mu \mathrm{m} / 7 \mathrm{kN} / \mathrm{cm}$ \\
\hline
\end{tabular}


Acknowledgments This work was supported by the Drug Delivery Innovation Center (DDIC), INVITE GmbH, Leverkusen. The author thanks Malvern Panalytical for supporting this work and DFE Pharma for supplying the excipient SuperTab® $21 \mathrm{AN}$.

Funding Open Access funding enabled and organized by Projekt DEAL.

\section{Compliance with Ethical Standards}

Disclosure of Potential Conflicts of Interest The authors declare that they have no conflict of interest.

Open Access This article is licensed under a Creative Commons Attribution 4.0 International License, which permits use, sharing, adaptation, distribution and reproduction in any medium or format, as long as you give appropriate credit to the original author(s) and the source, provide a link to the Creative Commons licence, and indicate if changes were made. The images or other third party material in this article are included in the article's Creative Commons licence, unless indicated otherwise in a credit line to the material. If material is not included in the article's Creative Commons licence and your intended use is not permitted by statutory regulation or exceeds the permitted use, you will need to obtain permission directly from the copyright holder. To view a copy of this licence, visit http://creativecommons.org/licenses/by/4.0/.

\section{References}

1. Lee SL, O'Connor TF, Yang XC, Cruz CN, Chatterjee S, Madurawe RD, et al. Modernizing pharmaceutical manufacturing: from batch to continuous production. J Pharm Innov. 2015;10(3): 191-9. https://doi.org/10.1007/s12247-015-9215-8.

2. Lee SL. Current FDA perspective for continuous manufacturing [conference presentation]. MIT-CMAC 2nd International Symposium on Continuous Manufacturing of Pharmaceuticals, September 26-27, 2016; Cambridge, MA, USA2016.

3. Plumb K. Continuous processing in the pharmaceutical industry changing the mind set. Chemical Engineering Research \& Design. 2005;83(A6):730-8. https://doi.org/10.1205/cherd.04359.

4. Rantanen J, Khinast J. The future of pharmaceutical manufacturing sciences. J Pharm Sci. 2015;104(11):3612-38. https://doi.org/10. 1002/jps.24594.

5. Lee SL. Quality Considerations for Continuous Manufacturing Guidance for Industry. Food and Drug Administration. 2019. https://www.fda.gov/media/121314/download. Accessed 03.08. 2020 08:27.

6. U.S. Food and Drug Administration. Guidance for industry, PAT- a framework for innovative pharmaceutical development, manufacturing and quality assurance. 2004. https://www.fda.gov/ media/71012/download. Accessed 03.08.2020.

7. U.S. Food and Drug Administration. Advancement of emerging technology applications for pharmaceutical innovation and modernization: guidance for industry. 2017. https://www.fda.gov/files/ drugs/published/Advancement-of-Emerging-TechnologyApplications-for-Pharmaceutical-Innovation-and-ModernizationGuidance-for-Industry.pdf. Accessed 03.08.2020.

8. European Medicines Agency. Guideline on real-time release testing (formerly guideline on parametric release) - Revision 1. 2012. https://www.ema.europa.eu/en/documents/scientific-guideline/ guideline-real-time-release-testing-formerly-guideline-parametricrelease-revision-1_en.pdf. Accessed 03.08.2020 08:36.
9. European Medicines Agency. Guideline on manufacture of the finished dosage form 2017. https://www.ema.europa.eu/en/ documents/scientific-guideline/guideline-manufacture-finisheddosage-form-revision-1_en.pdf. Accessed 03.08.2020 08:37.

10. The International Council for Harmonisation. ICH Q10 Pharmaceutical Quality System. 2015. https:/www.ema.europa. $\mathrm{eu} / \mathrm{en} /$ documents/scientific-guideline/international-conferenceharmonisation-technical-requirements-registrationpharmaceuticals-human_en.pdf.

11. The International Council for Harmonisation. ICH Q8 Pharmaceutical development. 2017. https://www.ema.europa.eu/ en/documents/scientific-guideline/international-conferenceharmonisation-technical-requirements-registrationpharmaceuticals-human-use_en-11.pdf. Accessed 03.08.2020.

12. Zwolensky-Lambert W. Update on ICH Q13. 2nd Continuous Manufacturing Conference; February 18, 2020; Freiburg im Breisgau.

13. Hlinak AJ, Kuriyan K, Morris KR, Reklaitis GV, Basu PK. Understanding critical material properties for solid dosage form design. J Pharm Innov. 2006;1(1):12-7. https://doi.org/10.1007/ bf02784876.

14. Fonteyne M, Vercruysse J, De Leersnyder F, Van Snick B, Vervaet $\mathrm{C}$, Remon JP, et al. Process analytical technology for continuous manufacturing of solid-dosage forms. Trac-Trends in Analytical Chemistry. 2015;67:159-66. https://doi.org/10.1016/j.trac.2015. 01.011.

15. Leane M, Pitt K, Reynolds G. A proposal for a drug product manufacturing classification system (MCS) for oral solid dosage forms. Pharm Dev Technol. 2015;20(1):12-21. https://doi.org/10. 3109/10837450.2014.954728.

16. Kleinebudde P. Roll compaction/dry granulation: pharmaceutical applications. Eur J Pharm Biopharm. 2004;58(2):317-26. https:// doi.org/10.1016/j.ejpb.2004.04.014.

17. Sun C, Himmelspach MW. Reduced tabletability of roller compacted granules as a result of granule size enlargement. J Pharm Sci. 2006;95(1):200-6. https://doi.org/10.1002/jps.20531.

18. Mosig J, Kleinebudde P. Critical evaluation of root causes of the reduced compactability after roll compaction/dry granulation. J Pharm Sci. 2015;104(3):1108-18. https://doi.org/10.1002/jps. 24321.

19. Sun C, Kleinebudde P. Mini review: mechanisms to the loss of tabletability by dry granulation. Eur J Pharm Biopharm. 2016;106:9-14. https://doi.org/10.1016/j.ejpb.2016.04.003.

20. Shekunov BY, Chattopadhyay P, Tong HH, Chow AH. Particle size analysis in pharmaceutics: principles, methods and applications. Pharm Res. 2007;24(2):203-27. https://doi.org/10.1007/ s11095-006-9146-7.

21. Alderliesten M. Mean particle diameters. Part IV: empirical selection of the proper type of mean particle diameter describing a product or material property. Part Part Syst Charact. 2004;21(3):179-96. https://doi.org/10.1002/ppsc.200400917.

22. Madarasz L, Nagy ZK, Hoffer I, Szabo B, Csontos I, Pataki H, et al. Real-time feedback control of twin-screw wet granulation based on image analysis. Int J Pharm. 2018;547(1-2):360-7. https://doi.org/ 10.1016/j.jpharm.2018.06.003.

23. Chan LW, Tan LH, Heng PWS. Process analytical technology: application to particle sizing in spray drying. AAPS PharmSciTech. 2008;9(1):259-66. https://doi.org/10.1208/ s12249-007-9011-y.

24. Nalluri VR, Schirg P, Gao X, Virdis A, Imanidis G, Kuentz M. Different modes of dynamic image analysis in monitoring of pharmaceutical dry milling process. Int J Pharm. 2010;391(1-2):10714. https://doi.org/10.1016/j.ijpharm.2010.02.027.

25. Greaves D, Boxall J, Mulligan J, Montesi A, Creek J, Sloan ED, et al. Measuring the particle size of a known distribution using the 
focused beam reflectance measurement technique. Chem Eng Sci. 2008;63(22):5410-9. https://doi.org/10.1016/j.ces.2008.07.023.

26. Närvänen T, Lipsanen T, Antikainen $O$, Räikkönen H, Heinämäki J, Yliruusi J. Gaining fluid bed process understanding by in-line particle size analysis. J Pharm Sci. 2009;98(3):1110-7. https://doi. org/10.1002/jps.21486.

27. Petrak D. Simultaneous measurement of particle size and particle velocity by the spatial filtering technique. Part Part Syst Charact. 2002;19(6):391-400. https://doi.org/10.1002/ppsc.200290002.

28. Mangal H, Derksen E, Lura A, Kleinebudde P. In-line particle size measurement in dry granulation: Evaluation of probe position. 10th World Meeting on Pharmaceutics, Biopharmaceutics and Pharmaceutical Technology. 2016.

29. Wilms A, Kleinebudde P. Particle size distribution in the product stream after roll compaction/dry granulation. 3rd European Conference on Pharmaceutics; Bologna2019.

30. Mangal H. Implementierung der Trockengranulierung in eine kontinuierliche Produktionsanlage für feste Arzneiformen. $\mathrm{PhD}$ thesis in german, title translates to "Implementation of dry granulation in a continuous manufacturing line for solid oral dosage forms". PhD thesis Heinrich Heine University Düsseldorf. 2018.

31. McAuliffe MAP, O'Mahony GE, Blackshields CA, Collins JA, Egan DP, Kiernan L, et al. The use of PAT and off-line methods for monitoring of roller compacted ribbon and granule properties with a view to continuous processing. Org Process Res Dev. 2015;19(1):158-66. https://doi.org/10.1021/op5000013.

32. Wilms A, Knop K, Kleinebudde P. Combination of a rotating tube sample divider and dynamic image analysis for continuous on-line determination of granule size distribution. Int J Pharm X. 2019;1: 100029. https://doi.org/10.1016/j.ijpx.2019.100029.

33. Wilms A, Meier; R., Kleinebudde, P. Development and Evaluation of an In-line and On-line Monitoring System for Granule Size Distributions in Continuous Roll Compaction/Dry Granulation Based on Laser Diffraction. J Pharm Innov. 2020. https://doi.org/ 10.1007/s12247-020-09443-3.

34. Wiedey R, Šibanc R, Wilms A, Kleinebudde P. How relevant is ribbon homogeneity in roll compaction/dry granulation and can it be influenced? Eur J Pharm Biopharm. 2018;133:232-9. https:// doi.org/10.1016/j.ejpb.2018.10.021.

35. Freitag F, Reincke K, Runge J, Grellmann W, Kleinebudde P. How do roll compaction/dry granulation affect the tableting behaviour of inorganic materials?: microhardness of ribbons and mercury porosimetry measurements of tablets. Eur J Pharm Sci. 2004;22(4):325-33. https://doi.org/10.1016/j.ejps.2004.04.001.

36. Wiedey R, Kleinebudde P. Infrared thermography - a new approach for in-line density measurement of ribbons produced from roll compaction. Powder Technol. 2017;337:17-24. https://doi.org/ 10.1016/j.powtec.2017.01.052.

37. Wiedey R, Kleinebudde P. Potentials and limitations of thermography as an in-line tool for determining ribbon solid fraction. Powder Technol. 2018;341:2-10. https://doi.org/10.1016/j.powtec.2018. 03.047 .
38. Wilms A, Kleinebudde P. Towards better understanding of the influence of process parameters in roll compaction/dry granulation on throughput, ribbon microhardness and granule failure load. Int $\mathrm{J}$ Pharm X. 2020;100059:100059. https://doi.org/10.1016/j.ijpx. 2020.100059

39. Singh R, Ierapetritou M, Ramachandran R. An engineering study on the enhanced control and operation of continuous manufacturing of pharmaceutical tablets via roller compaction. Int J Pharm. 2012;438(1-2):307-26. https://doi.org/10.1016/j.ijpharm.2012.09. 009.

40. Mangal $\mathrm{H}$, Kleinebudde $\mathrm{P}$. Is the adjustment of the impeller speed a reliable attempt to influence granule size in continuous dry granulation? Adv Powder Technol. 2018;29(6):1339-47. https://doi.org/ 10.1016/j.apt.2018.02.029.

41. Reimers T, Thies J, Stöckel P, Dietrich S, Pein-Hackelbusch M, Quodbach J. Implementation of real-time and in-line feedback control for a fluid bed granulation process. Int J Pharm. 2019;567: 118452. https://doi.org/10.1016/j.ijpharm.2019.118452.

42. Reimers T, Thies J, Dietrich S, Quodbach J, Pein-Hackelbusch M. Evaluation of in-line particle measurement with an SFT-probe as monitoring tool for process automation using a new time-based buffer approach. Eur J Pharm Sci. 2019;128:162-70. https://doi. org/10.1016/j.ejps.2018.11.026.

43. Agachi PS, Cristea MV. Basic process engineering control. Walter de Gruyter GmbH \& Co KG: Berlin/Boston; 2014.

44. Sun CC. Mechanism of moisture induced variations in true density and compaction properties of microcrystalline cellulose. Int $\mathrm{J}$ Pharm. 2008;346(1-2):93-101. https://doi.org/10.1016/j.ijpharm. 2007.06.017.

45. Sun CC. Quantifying effects of moisture content on flow properties of microcrystalline cellulose using a ring shear tester. Powder Technol. 2016;289:104-8. https://doi.org/10.1016/j.powtec.2015. 11.044.

46. Shah A, Mlodozeniec A. Mechanism of surface lubrication: influence of duration of lubricant-excipient mixing on processing characteristics of powders and properties of compressed tablets. J Pharm Sci. 1977;66(10):1377-82. https://doi.org/10.1002/jps. 2600661006.

47. Billany M, Richards J. Batch variation of magnesium stearate and its effect on the dissolution rate of salicylic acid from solid dosage forms. Drug Dev Ind Pharm. 1982;8(4):497-511. https://doi.org/ $10.3109 / 03639048209022117$

48. Mosig J, Kleinebudde P. Evaluation of lubrication methods: how to generate a comparable lubrication for dry granules and powder material for tableting processes. Powder Technol. 2014;266:15666. https://doi.org/10.1016/j.powtec.2014.06.022.

Publisher's Note Springer Nature remains neutral with regard to jurisdictional claims in published maps and institutional affiliations. 